\title{
Assessment of Systemic Inflammatory Response and Nutritional Markers in Patients With Trastuzumab-treated Unresectable Advanced Gastric Cancer
}

\author{
TSUTOMU NAMIKAWA ${ }^{1}$, MASAHIRO MAEDA ${ }^{1}$, KEIICHIRO YOKOTA $^{1}$, NOBUHISA TANIOKA ${ }^{1}$, \\ IAN FUKUDOME ${ }^{1}$, JUN IWABU ${ }^{1}$, MASAYA MUNEKAGE ${ }^{1}$, SUNAO UEMURA ${ }^{1}$, HIROMICHI MAEDA ${ }^{1}$, \\ HIROYUKI KITAGAWA ${ }^{1}$, MICHIYA KOBAYASHI ${ }^{2}$ and KAZUHIRO HANAZAKI ${ }^{1}$ \\ ${ }^{1}$ Department of Surgery, Kochi Medical School, Kochi, Japan; \\ ${ }^{2}$ Department of Human Health and Medical Sciences, Kochi Medical School, Kochi, Japan
}

\begin{abstract}
Aim: To determine whether markers of systemic inflammatory response and nutrition are a predictor of treatment response in patients with trastuzumab-treated unresectable advanced gastric cancer. Patients and Methods: Twenty-one patients who received chemotherapy for unresectable advanced gastric cancer at Kochi Medical School from 2013 to 2020 were enrolled. Clinicopathological information and systemic inflammatory response data were obtained retrospectively to investigate associations between baseline cancer-related prognostic variables and survival outcomes. Results: The median overall survival (OS) and progression-free survival (PFS) for the whole cohort were 24.5 (range=1.9-88.4) months and 7.0 (range=2.0-23.4) months, respectively. The objective response rate and disease control rate were $52.4 \%$ and $81.0 \%$, respectively. The median PFS for patients with a neutrophil to lymphocyte ratio (NLR) $<2.8$ was significantly longer than that for those with NLR $\geq 2.8$ (8.9 vs. 6.0 months; $p=0.048$ ). Although the median OS also tended to be longer for patients with $N L R<2.8$, the difference was not statistically significant. No significant differences in median OS and PFS were observed between patients with a prognostic nutrition index (PNI) $<41.6$ and those with PNI $\geq 41.6$. Conclusion: An NLR $\geq 2.8$ is a predictor of poorer prognosis in patients receiving systemic
\end{abstract}

This article is freely accessible online.

Correspondence to: Tsutomu Namikawa, Department of Surgery, Kochi Medical School, Kohasu, Oko-cho, Nankoku, Kochi 7838505, Japan. Tel: +81 888802370, Fax: +81 888802371, e-mail: tsutomun@kochi-u.ac.jp

Key Words: Gastric cancer, Glasgow prognostic score, neutrophil to lymphocyte ratio, prognostic nutrition index, prognostic value, survival. treatment with trastuzumab and chemotherapy for unresectable advanced or recurrent gastric cancer.

Gastric cancer is one of the most common malignant tumors and the seventh leading cause of cancer-related deaths worldwide; it is also the second-most frequent cause of cancer-related deaths in Japan (1-3). Systemic anti-neoplastic treatment including chemotherapy or molecular-targeted drug therapy improves survival and possibly provides significant palliation of symptoms compared with best supportive care alone, which is recommended as the standard treatment in patients with unresectable advanced or recurrent gastric cancer (4).

Human epidermal growth factor receptor 2 (HER2), which is associated with cell proliferation, apoptosis and differentiation, is used in clinical practice for targeted therapy. According to the randomized phase III ToGA trial, HER2 expression was predictive for the success of treatment with trastuzumab, a monoclonal antibody against HER2, in advanced gastric cancer (5). Treatment with trastuzumab with adjunct chemotherapy consisting of capecitabine plus cisplatin has been shown to yield promising results in patients with HER2-positive first-line metastatic advanced gastric cancer $(5,6)$.

Recent studies have identified the prognostic impact of inflammatory response and nutritional status on the survival of patients with many types of malignant solid tumors, as demonstrated by indices such as the Glasgow prognostic score (GPS), prognostic nutrition index (PNI), and neutrophil to lymphocyte ratio (NLR) (7-10). However, information regarding the prognostic significance of these inflammatory response and nutritional markers for patients with unresectable advanced or recurrent gastric cancer receiving systemic treatment with trastuzumab and chemotherapy is lacking. Therefore, in the present study, we retrospectively analyzed a range of clinicopathological factors including the 
GPS, PNI, and NLR for any association between these factors and the prognosis of such patients.

\section{Patients and Methods}

Patients. Twenty-one patients with unresectable advanced gastric cancer who were treated with trastuzumab at the Kochi Medical School during the period from January 2013 to December 2020 were identified from a medical information database. Gastric cancer diagnoses were determined by esophagogastroduodenoscopy, biopsy specimen analysis, computed tomography, magnetic resonance imaging, ultrasonography of the abdomen, and positron-emission tomography.

Patients with gastric cancer were treated with trastuzumab plus chemotherapy as first-line therapy when their tumor samples were scored as $3+$ for HER 2 by immunohistochemistry, or if their tumor samples were scored 2+ and were positive by fluorescent in situ hybridization analysis.

Blood samples were collected for analysis of serum concentrations of albumin and C-reactive protein (CRP), and for neutrophil and lymphocyte cell counts. Tumor histology was categorized as intestinal type (well-differentiated, moderately differentiated, and papillary adenocarcinoma) or diffuse type (poorly differentiated, mucinous adenocarcinoma, and signet ring cell carcinoma) according to Lauren's classification (11).

Objective tumor response was evaluated in patients with target lesions according to the Response Evaluation Criteria in Solid Tumors (RECIST) version 1.1 (12), and the assessment was repeated every 6 to 8 weeks after initiation of trastuzumab therapy using computed tomography.

The overall survival (OS) and progression free survival (PFS) after treatment were both determined as described below (Statistical analyses section). OS was calculated from the initiation of systemic anti-neoplastic treatment until death or the last follow-up consultation. PFS was defined as the time from trastuzumab treatment initiation as first-line therapy to objective disease progression.

The study was approved by the Institutional Review Board at the Kochi Medical School Hospital (approval number: 2020-6) and was conducted in accordance with the Declaration of Helsinki and the Japanese Good Clinical Practice Guidelines. Informed consent was obtained from all participants in the study.

Measurement of systemic inflammation and nutrition-related variables. Venous blood samples were taken at the time of diagnosis and during trastuzumab treatment, and the percentages of each type of blood cell were determined from blood smears stained with Giemsa's reagent. The systemic inflammatory response and nutrition status, as determined by the NLR, PNI, and GPS, were calculated.

NLR was defined as the neutrophil count divided by the lymphocyte count. The GPS and PNI were constructed as previously described to evaluate inflammatory status prior to chemotherapy, and to determine which of the two scores demonstrated a better correlation with prognosis in patients with gastric cancer $(7,13)$. GPS was determined as follows: Patients with elevated CRP $(>1.0$ $\mathrm{mg} / \mathrm{dl})$ and hypoalbuminemia $(<3.5 \mathrm{~g} / \mathrm{dl})$ were allocated a score of 2 ; patients with only one of these biochemical abnormalities were allocated a score of 1 ; and patients with neither of these abnormalities were allocated a score of 0 (8). PNI was calculated
Table I. Clinical characteristics of patients $(n=21)$ who underwent trastuzumab therapy for unresectable gastric cancer.

\begin{tabular}{|c|c|c|}
\hline Age, years & Median (range) & $68(36-83)$ \\
\hline \multirow[t]{2}{*}{ Gender, $\mathrm{n}$} & Male & 16 \\
\hline & Female & 5 \\
\hline \multirow[t]{2}{*}{ Histology, n } & Intestinal type & 15 \\
\hline & Diffuse type & 6 \\
\hline \multirow[t]{3}{*}{ Metastasis site, $\mathrm{n}$} & $\begin{array}{l}\text { Hematogenous } \\
\text { (liver, lung, bone) }\end{array}$ & 13 \\
\hline & Peritoneum & 5 \\
\hline & Lymph node & 3 \\
\hline \multirow[t]{2}{*}{ Disease status, $n$} & Initially metastatic & 15 \\
\hline & $\begin{array}{l}\text { Recurrent after } \\
\text { curative }\end{array}$ & 6 \\
\hline \multicolumn{3}{|l|}{ Laboratory examinations } \\
\hline Albumin (mg/dl) & Median (range) & $4.1(2.7-4.9)$ \\
\hline C-Reactive protein, $\mathrm{mg} / \mathrm{dl}$ & Median (range) & $0.4(0.05-5.9)$ \\
\hline $\begin{array}{l}\text { White blood cell count, } \\
\mathrm{n} / \mathrm{mm}^{3}\end{array}$ & Median (range) & $6,900(3,200-12,200$ \\
\hline Neutrophil count, $\mathrm{n} / \mathrm{mm}^{3}$ & Median (range) & $4,540(1,710-10,180$ \\
\hline Lymphocyte count, $\mathrm{n} / \mathrm{mm}^{3}$ & Median (range) & $1,560(970-3,230)$ \\
\hline \multicolumn{3}{|l|}{ Serum tumor markers } \\
\hline CEA, ng/ml & Median (range) & $8.9(0.9-671.1)$ \\
\hline CA19-9, U/ml & Median (range) & $27.6(4.1-891.3)$ \\
\hline CA125, U/ml & Median (range) & $18.7(7.0-308.8)$ \\
\hline \multicolumn{3}{|l|}{$\begin{array}{l}\text { Inflammatory response } \\
\text { and nutritional biomarkers }\end{array}$} \\
\hline \multirow[t]{3}{*}{ GPS, n } & 0 & 17 \\
\hline & 1 & 3 \\
\hline & 2 & 1 \\
\hline NLR & Median (range) & $2.8(1.1-9.2)$ \\
\hline PNI & Median (range) & $41.1(27.1-49.1)$ \\
\hline
\end{tabular}

CA: Carbohydrate antigen; CEA: carcinoembryonic antigen; GPS: Glasgow prognostic score; NLR: neutrophil to lymphocyte ratio; PNI: prognostic nutrition index.

using the following formula: $\mathrm{PNI}=$ serum albumin level $(\mathrm{g} / \mathrm{l})+[5 \times$ total lymphocyte count $(\mathrm{n} / \mathrm{l})](14)$.

Statistical analyses. We tested differences in mean values between groups of patients for significance using a Mann-Whitney $U$-test for continuous variables and Pearson's chi-squared test for categorical variables. The Kaplan-Meier method was used to generate cumulative survival rates and compared them using the log-rank test to evaluate significant differences. Statistical analyses were performed using SPSS for Windows, version 22.0 (IBM, Armonk, NY, USA). A multivariate Cox proportional hazards regression analysis was used to identify factors independently associated with survival. For the subgroup analysis of OS, hazard ratio (HR) and 95\% confidence interval (CI) within each subgroup were summarized. When the various factors were considered in a multivariate analysis, all were dichotomized according to the univariate analysis.

\section{Results}

Patient characteristics. Table I summarizes the clinical characteristics of patients with unresectable advanced gastric 
A

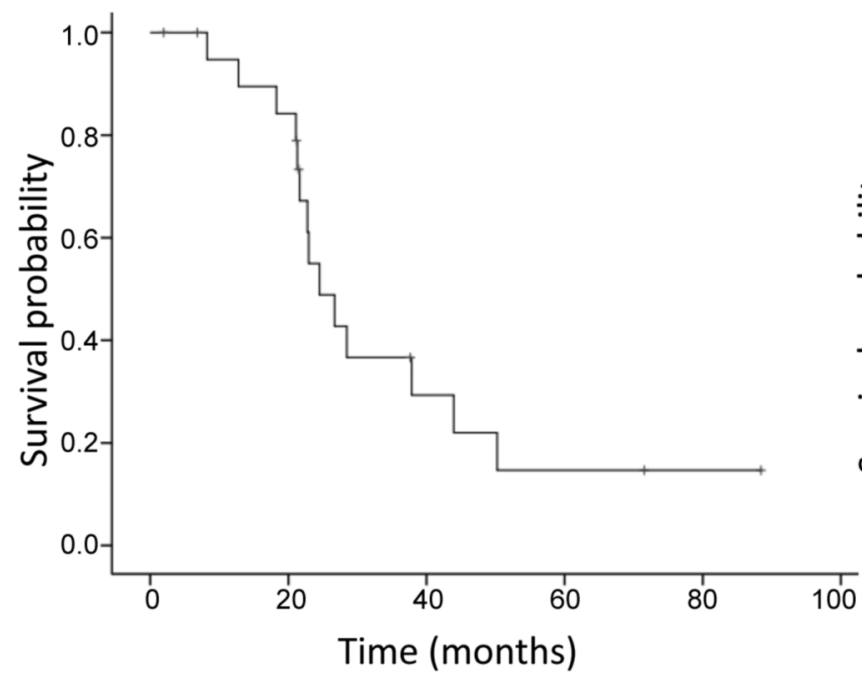

B

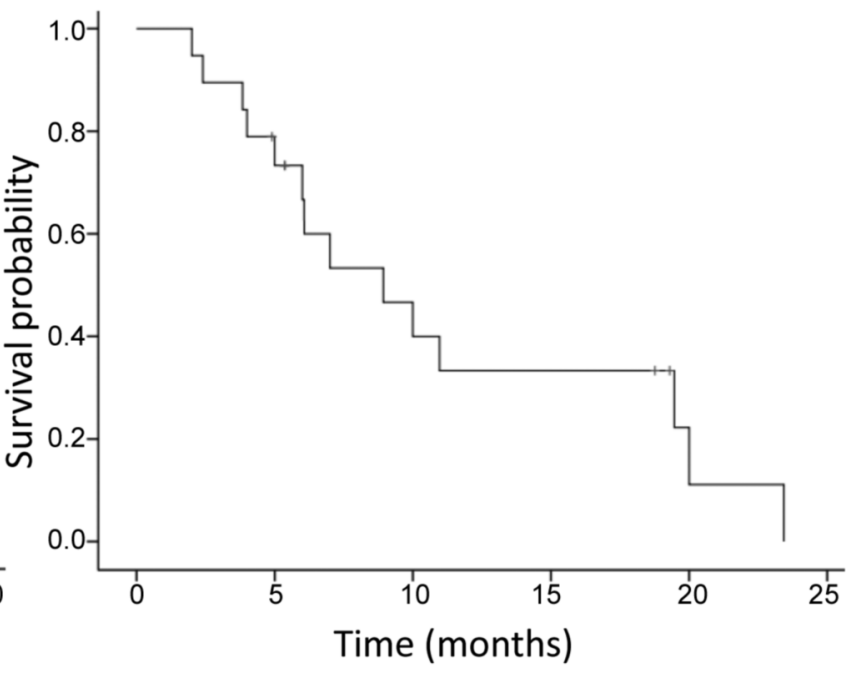

Figure 1. Kaplan-Meier survival analysis for patients overall. Kaplan-Meier estimates of overall (A) and progression-free (B) survival in patients with unresectable advanced gastric cancer who were treated with trastuzumab and chemotherapy. Median overall survival was 24.5 (range $=1.9$ 88.4) months and median progression-free survival was 7.0 (range=2.0-23.4) months.

cancer included in the present study. The study cohort comprised 16 men and five women, with a median age of 68 years (range $=36-83$ years). Of these 21 patients, 15 had intestinal type tumor and 6 diffuse type tumor. Metastasis was mainly hematogenous (13 patients). At diagnosis, 15 patients were classified as having metastatic cancer and six were classified as having recurrent cancer, following curative resection of gastric cancer. Eastern Cooperative Oncology Group performance status was 0 in 20 patients, 1 in one patient, and the median follow-up period for survivors was 22.8 months. Among the 21 patients for whom the response assessment using target lesions was evaluable, a complete response $(\mathrm{CR})$ was observed in 0 patients, a partial response (PR) in 11 patients $(52.4 \%)$, stable disease (SD) in 6 patients (28.6\%), and progressive disease (PD) in 4 patients (19.0\%), resulting in an objective response rate (ORR) of $52.4 \%$ and a disease control rate of $81.0 \%$.

All patients were shifted to second-line chemotherapy using taxanes with or without ramucirumab, or irinotecan after evidence of disease progression. The median OS for the whole cohort was 24.5 (range=1.9-88.4) months and the OS rate at 1,2 , and 3 years after therapy was $89.5 \%, 48.9 \%$ and $29.3 \%$, respectively (Figure 1A). The median PFS for the whole cohort was 7.0 (range=2.0-23.4) months (Figure 1B).

The median pretreatment NLR and PNI values for the whole cohort were 2.8 (range=1.1-9.2) and 41 .1 (range=27.149.1 ), respectively. There was no significant influence on OS and PFS by age, gender, disease status, metastatic site, or time to recurrence, according to the results of the univariate analysis (Table II).
Association of systemic inflammatory markers and patient survival. Because the median pretreatment NLR for the whole cohort was 2.8 , patients were divided into two groups based on their pretreatment NLR, i.e. NLR $<2.8$ and $\geq 2.8$. Similarly, as the median pretreatment PNI was 41.1 , patients were divided into two groups based on their pretreatment PNI (PNI <41.1 and PNI $\geq 41.1$ ). The median OS for patients with NLR $<2.8$ was 28.5 months, which was longer than that for those with $\mathrm{NLR} \geq 2.8$ (22.9 months), although the difference did not reach statistical significance $(p=0.119$; Figure 2A). The median PFS for patients with NLR $<2.8$ was 8.9 months and was significantly longer than the that for those with NLR $\geq 2.8$ (6.0 months; $p=0.048$; Figure $2 \mathrm{~B})$. No significant difference was observed in median OS (21.6 vs. 22.9 months; $p=0.731$ ) or PFS (8.9 vs. 12.1 months; $p=0.814)$ between patients with a PNI $<41.6$ and those with a PNI $\geq 41.6$ (Figure 3).

\section{Discussion}

We found that NLR $\geq 2.8$ predicted poor prognosis in patients with unresectable advanced or recurrent gastric cancer who received systemic treatment with trastuzumab and chemotherapy. Thus, a high NLR score may have important implications in clinical practice.

Although trastuzumab in combination with platinum-based chemotherapy is the standard first-line regimen in HER2positive advanced gastric cancer, predictive markers of treatment have not been established $(5,6)$. To the best of our knowledge, this is the first study to demonstrate a 
Table II. Overall and progression free survival of patients treated with trastuzumab for unresectable or recurrent gastric cancer using univariate analysis.

\begin{tabular}{|c|c|c|c|c|c|}
\hline \multirow[t]{2}{*}{ Variable } & & \multicolumn{2}{|c|}{ Overall survival } & \multicolumn{2}{|c|}{ Progression-free survival } \\
\hline & & $\mathrm{HR}(95 \% \mathrm{CI})$ & $p$-Value & HR $(95 \% \mathrm{CI})$ & $p$-Value \\
\hline \multirow[t]{2}{*}{ Age group } & $<68$ Years & 1 & & 1 & \\
\hline & $\geq 68$ Years & $1.119(0.390-3.209)$ & 0.834 & $1.262(0.420-3.794)$ & 0.678 \\
\hline \multirow{2}{*}{ Gender } & Male & 1 & & 1 & \\
\hline & Female & $1.512(0.398-5.747)$ & 0.544 & $1.443(0.379-5.499)$ & 0.591 \\
\hline \multirow[t]{2}{*}{ Histological type } & Intestinal type & 1 & & 1 & \\
\hline & Diffuse type & $0.654(0.199-2.149)$ & 0.485 & $1.471(0.427-5.062)$ & 0.541 \\
\hline \multirow[t]{3}{*}{ Metastasis site } & Hematogenous (liver, lung, bone) & 1 & & 1 & \\
\hline & Peritoneum & $2.241(0.443-11.340)$ & 0.329 & $3.311(0.403-27.194)$ & 0.265 \\
\hline & Lymph node & $4.485(0.657-30.612)$ & 0.126 & $5.368(0.565-51.031)$ & 0.144 \\
\hline \multirow[t]{2}{*}{ Disease status } & Initially metastatic & 1 & & 1 & \\
\hline & Recurrent after curative & $2.298(0.665-7.938)$ & 0.188 & $1.251(0.377-4.158)$ & 0.714 \\
\hline \multirow[t]{2}{*}{ GPS } & 0 & 1 & & 1 & \\
\hline & 1 or 2 & $2.605(0.503-13.500)$ & 0.254 & $1.340(0.287-6.248)$ & 0.709 \\
\hline \multirow[t]{2}{*}{ NLR } & $<2.8$ & 1 & & 1 & \\
\hline & $\geq 2.8$ & $2.576(0.784-8.465)$ & 0.119 & $3.777(1.012-14.095)$ & 0.048 \\
\hline \multirow[t]{2}{*}{ PNI } & $<41.1$ & 1 & & 1 & \\
\hline & $\geq 41.1$ & $0.828(0.282-2.431)$ & 0.731 & $0.869(0.271-2.790)$ & 0.814 \\
\hline
\end{tabular}

CI: Confidence intervaI; GPS: Glasgow prognostic score; HR: hazard ratio; NLR: neutrophil to lymphocyte ratio; PNI: prognostic nutrition index.

relationship between inflammatory response and prognosis in patients with unresectable advanced or recurrent gastric cancer who had received trastuzumab with chemotherapy.

Previous studies have reported that the HER2 overexpression rate in patients with gastric cancer was $17-18 \%$ and was significantly associated with a high grade, advanced stage, and a high Ki-67 labeling index (15-17). Kurokawa et al. evaluated 1, 148 patients with gastric cancer who underwent gastrectomy to investigate the prognostic impact of HER2 expression, demonstrating HER2 overexpression to be an independent prognostic factor in patients with any stage of gastric cancer (18). In the present study, the median OS and PFS were 24.5 months and 7.0 months, respectively; both values are relatively longer compared to survival times of patients with common type unresectable gastric cancer, despite the unfavorable prognostic factor of HER2 overexpression. Thus, patients with HER2 overexpression who undergo trastuzumab treatment with chemotherapy may be expected to benefit from longer survival times.

Recently, Hwang et al. reported that a high NLR was associated with a shorter PFS and OS in trastuzumab-treated patients with HER2-positive gastric cancer, when the cut-off value of NLR was set to 3.0 (19). In the present study, although patients with an NLR $\geq 2.8$ tended to have poorer prognosis than those with an NLR $<2.8$ (median OS: $22.9 \mathrm{vs}$. 28.5 months, respectively), the difference was not significant $(p=0.119)$. The recent development of second- and furtherline treatments for unresectable advanced gastric cancer, including ramucirumab, nivolumab, and trifluridine/tipiracil, has improved OS and quality of life (20-23). Therefore, improvement in post-progression survival after first-line treatment using trastuzumab may result in the loss of prognostic significance in OS.

Although the mechanism by which systemic inflammatory response markers influence cancer survival in these patients remain unclear, it is possible that pretreatment neutrophil and lymphocyte numbers reflect the level of inflammation within the tumor (24). Evidence is accumulating that cancer progression is influenced by the systemic inflammatory response $(10,24,25)$. Furthermore, cytokines generated by neutrophils may establish a microenvironment that promotes angiogenesis, and thus promotes tumor growth and metastasis (25). An oncogenic change induces an inflammatory microenvironment that promotes the development of tumors, aids in the proliferation and survival of malignant cells, promotes angiogenesis and metastasis, subverts adaptive immune responses, and alters responses to hormones and chemotherapeutic agents (26).

Previous research from several laboratories has demonstrated that GPS and PNI, in addition to NLR, are predictors of oncological outcome in gastric cancer $(8,27-$ 29). The current study demonstrated that the median OS and PFS of patients with a high PNI tended to be prolonged (compared to those of patients with a low PNI), although the difference was not significant. A similar trend was found in GPS 0 compared to GPS 1 or 2 . Recent randomized phase III trial data demonstrated the superior predictive value (compared to traditional inflammatory indices) of a 
A

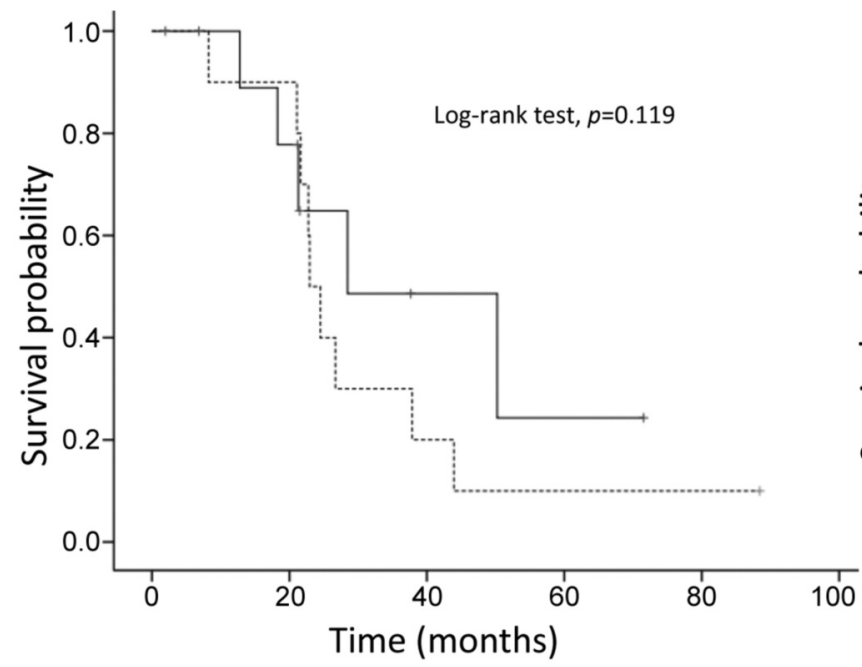

B

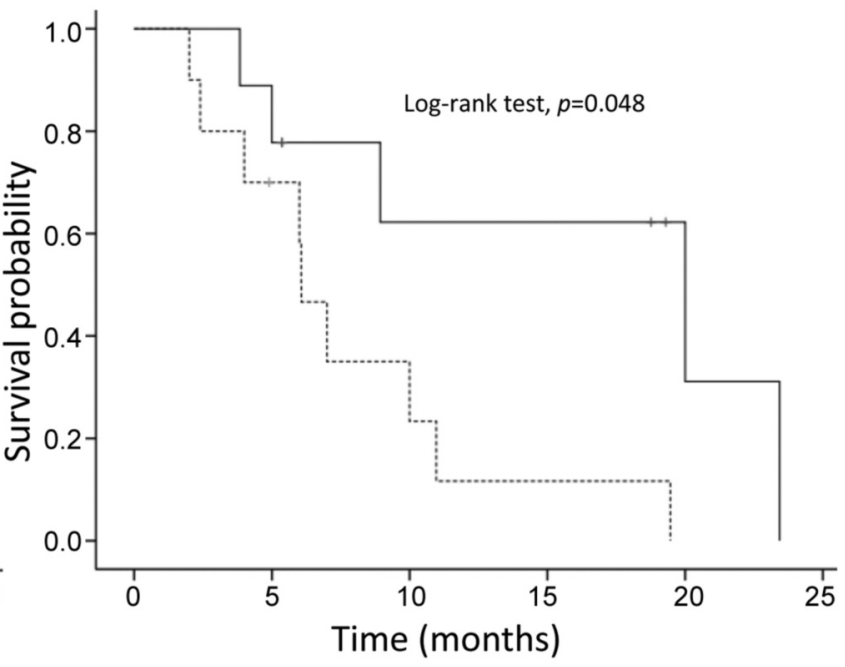

$N L R<2.8$

$N L R \geq 2.8$

Figure 2. Kaplan-Meier survival analysis according to the neutrophil to lymphocyte ratio (NLR). Kaplan-Meier estimates of overall (A) and progression-free $(B)$ survival according to NLR for patients with unresectable gastric cancer who were treated with trastuzumab and chemotherapy. No significant difference in overall survival was observed between patients with NLR $<2.8$ and those with NLR $\geq 2.8$ (28.5 vs. 22.9 months, hazard ratio $=2.58,95 \%$ confidence intervaI $=0.78-8.47 ; p=0.119$ ). The median progression-free survival was significantly higher for patients with NLR $<2.8$ (8.9 vs. 6.0 months, hazard ratio=3.78, 95\% confidence interval $=1.01-14.1 ; p=0.048$ ).

A

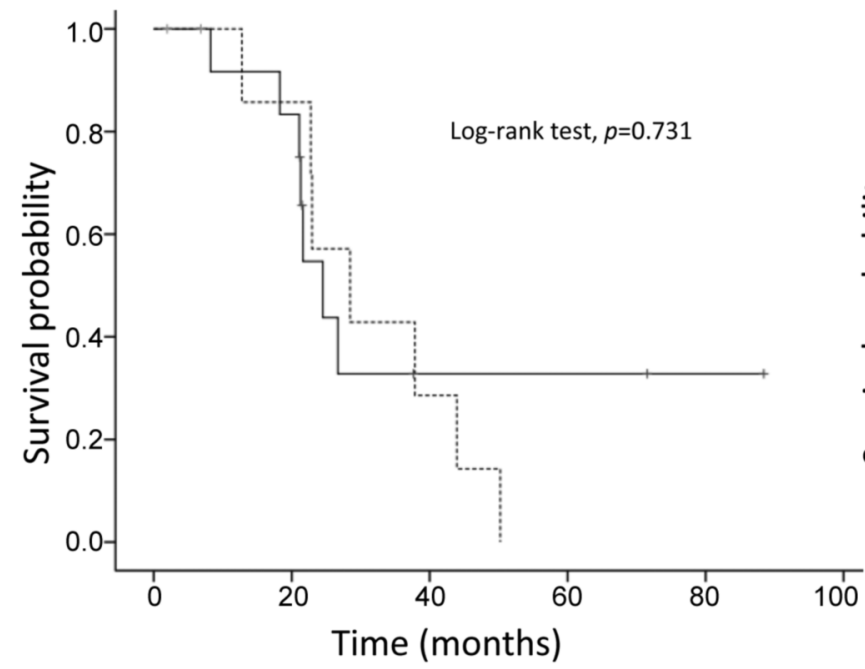

B

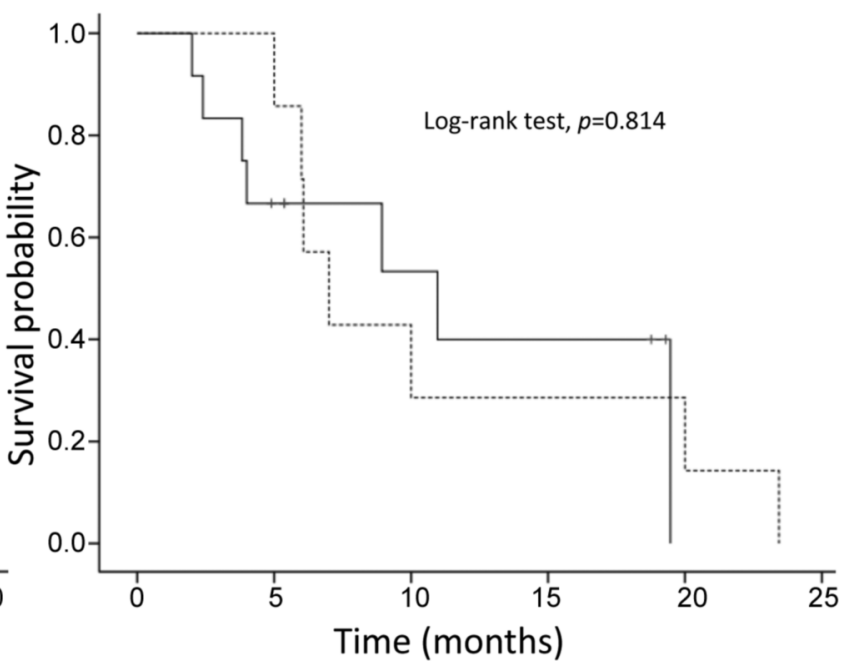

Figure 3. Kaplan-Meier survival analysis according to the prognostic nutrition index (PNI). Kaplan-Meier estimates of overall (A) and progressionfree (B) survival according to PNI for patients with unresectable gastric cancer who were treated with trastuzumab and chemotherapy. No significant differences in overall and progression-free survival were observed between patients with a PNI <41.1 and those with a PNI $\geq 41.1$ (21.6 vs. 22.9 months, hazard ratio $=0.83 ; 95 \%$ confidence intervaI $=0.28-2.43 ; p=0.731 ; 8.9$ vs. 12.1 months, hazard ratio $=0.87,95 \%$ confidence intervaI $=0.27-$ $2.79 ; p=0814$, respectively). 
combination of $\mathrm{C}$-reactive protein and serum albumin or prealbumin levels $(30,31)$. Accordingly, the development of a novel grading system based on previous systemic inflammatory responses and nutrition status may be expected to provide a more accurate prediction of patient survival.

There were several limitations in the present study. Firstly, due to the retrospective nature of this study, it is possible that selection bias may have influenced survival data. Secondly, this study was conducted at a single institution with a relatively small number of patients, which may also affect patient selection bias. Therefore, the results of this study should be interpreted cautiously. Accordingly, further welldesigned, prospective, multicenter validation studies with adequate statistical power and a larger number of patient subgroups are warranted to confirm our results.

In conclusion, a high NLR is associated with poorer survival times in patients with unresectable advanced or recurrent gastric cancer who received systemic treatment with trastuzumab and chemotherapy. Thus, NLR, a marker of inflammatory response, may serve as a useful biomarker for the prediction of patient prognosis. Further studies are needed to determine the reliability and accuracy of using NLR as a prognostic tool during trastuzumab treatment.

\section{Conflicts of Interest}

None.

\section{Authors' Contributions}

Study conception and design: Tsutomu Namikawa and Michiya Kobayashi. Acquisition of data: Tsutomu Namikawa, Masahiro Maeda, Keiichiro Yokota, Nobuhisa Tanioka, Jun Iwabu, Masaya Munekage, Sunao Uemura and Hiroyuki Kitagawa. Analysis and interpretation of data: Tsutomu Namikawa and Hiromichi Maeda. Drafting of manuscript: Tsutomu Namikawa. Critical revision of manuscript: Tsutomu Namikawa and Kazuhiro Hanazaki.

\section{References}

1 Nashimoto A, Akazawa K, Isobe Y, Miyashiro I, Katai H, Kodera Y, Tsujitani S, Seto Y, Furukawa H, Oda I, Ono H, Tanabe S and Kaminishi M: Gastric cancer treated in 2002 in Japan: 2009 Annual Report of the JGCA Nationwide Registry. Gastric Cancer 16(1): 1-27, 2013. PMID: 22729699. DOI: 10.1007/s10120-012-0163-4.

2 Fidler MM, Gupta S, Soerjomataram I, Ferlay J, SteliarovaFoucher E and Bray F: Cancer incidence and mortality among young adults aged 20-39 years worldwide in 2012: A populationbased study. Lancet Oncol 18(12): 1579-1589, 2017. PMID: 29111259. DOI: $10.1016 / \mathrm{S} 1470-2045(17) 30677-0$

3 Bray F, Ferlay J, Soerjomataram I, Siegel RL, Torre LA and Jemal A: Global cancer statistics 2018: GLOBOCAN estimates of incidence and mortality worldwide for 36 cancers in 185 countries. CA Cancer J Clin 68(6): 394-424, 2018. PMID: 30207593. DOI: $10.3322 /$ caac. 21492
4 Ohtsu A, Yoshida S and Saijo N: Disparities in gastric cancer chemotherapy between the East and West. J Clin Oncol 24(14): 2188-2196, 2006. PMID: 16682738. DOI: $10.1200 / \mathrm{JCO}$ 2006.05.9758

5 Bang YJ, Van Cutsem E, Feyereislova A, Chung HC, Shen L, Sawaki A, Lordick F, Ohtsu A, Omuro Y, Satoh T, Aprile G, Kulikov E, Hill J, Lehle M, Rüschoff J, Kang YK and ToGA Trial Investigators: Trastuzumab in combination with chemotherapy versus chemotherapy alone for treatment of HER2-positive advanced gastric or gastro-oesophageal junction cancer (ToGA): A phase 3, open-label, randomised controlled trial. Lancet 376(9742): 687-697, 2010. PMID: 20728210. DOI: $10.1016 / \mathrm{S} 0140-6736(10) 61121-\mathrm{X}$

6 Palle J, Tougeron D, Pozet A, Soularue E, Artru P, Leroy F, Dubreuil O, Sarabi M, Williet N, Manfredi S, Martin-Babau J, Rebischung C, Abdelghani MB, Evesque L, Dreanic J, Hautefeuille V, Louafi S, Sefrioui D, Savinelli F, Mabro M, Rousseau B, Lecaille C, Bouché O, Louvet C, Lecomte T, Bonnetain F, Taieb J and Zaanan A: Trastuzumab beyond progression in patients with HER2-positive advanced gastric adenocarcinoma: A multicenter AGEO study. Oncotarget 8(60): 101383-101393, 2017. PMID: 29254172. DOI: $10.18632 /$ oncotarget.20711

7 McMillan DC, Crozier JE, Canna K, Angerson WJ and McArdle CS: Evaluation of an inflammation-based prognostic score (GPS) in patients undergoing resection for colon and rectal cancer. Int J Colorectal Dis 22(8): 881-886, 2007. PMID: 17245566. DOI: $10.1007 / \mathrm{s} 00384-006-0259-6$

8 Namikawa T, Munekage E, Munekage M, Maeda H, Yatabe T, Kitagawa $\mathrm{H}$, Kobayashi $\mathrm{M}$ and Hanazaki $\mathrm{K}$ : Evaluation of systemic inflammatory response biomarkers in patients receiving chemotherapy for unresectable and recurrent advanced gastric cancer. Oncology 90(6): 321-326, 2016. PMID: 27225990. DOI: $10.1159 / 000446373$

9 Melling N, Grüning A, Tachezy M, Nentwich M, Reeh M, Uzunoglu FG, Vashist YK, Izbicki JR and Bogoevski D: Glasgow Prognostic Score may be a prognostic index for overall and perioperative survival in gastric cancer without perioperative treatment. Surgery 159(6): 1548-1556, 2016. PMID: 26899471. DOI: $10.1016 /$ j.surg.2016.01.018

10 Namikawa T, Yokota K, Yamaguchi S, Iwabu J, Munekage M, Uemura S, Tsujii S, Maeda H, Kitagawa H, Kumon M, Kobayashi $\mathrm{M}$ and Hanazaki K: Evaluation of systemic inflammatory response and nutritional biomarkers as predictive factors in patients with recurrent gastric cancer. Oncology, 2020. PMID: 32182616. DOI: 10.1159/000505973

11 Lauren P: The two histological main types of gastric carcinoma: Diffuse and so-called intestinal-type carcinoma. An attempt at a histoclinical classification. Acta Pathol Microbiol Scand 64: 3149, 1965. PMID: 14320675. DOI: 10.1111/apm.1965.64.1.31

12 Eisenhauer EA, Therasse P, Bogaerts J, Schwartz LH, Sargent D, Ford R, Dancey J, Arbuck S, Gwyther S, Mooney M, Rubinstein L, Shankar L, Dodd L, Kaplan R, Lacombe D and Verweij J: New Response Evaluation Criteria in Solid Tumours: Revised RECIST guideline (version 1.1). Eur J Cancer 45(2): 228-247, 2009. PMID: 19097774. DOI: 10.1016/j.ejca.2008.10.026

13 Wen J, Bedford M, Begum R, Mitchell H, Hodson J, Whiting J and Griffiths E: The value of inflammation based prognostic scores in patients undergoing surgical resection for oesophageal and gastric carcinoma. J Surg Oncol 117(8): 1697-1707, 2018. PMID: 29761518. DOI: 10.1002/jso.25057 
14 Sakurai K, Tamura T, Toyokawa T, Amano R, Kubo N, Tanaka H, Muguruma K, Yashiro M, Maeda K, Ohira M and Hirakawa $\mathrm{K}$ : Low preoperative prognostic nutritional index predicts poor survival post-gastrectomy in elderly patients with gastric cancer. Ann Surg Oncol 23(11): 3669-3676, 2016. PMID: 27207098. DOI: $10.1245 / \mathrm{s} 10434-016-5272-6$

15 Ieni A, Barresi V, Giuffrè G, Caruso RA, Lanzafame S, Villari L, Salomone E, Roz E, Cabibi D, Franco V, Certo G, Labate A, Nagar C, Magliolo E, Broggi B, Fazzari C, Italia F and Tuccari G: HER2 status in advanced gastric carcinoma: A retrospective multicentric analysis from Sicily. Oncol Lett 6(6): 1591-1594, 2013. PMID: 24260051. DOI: 10.3892/ol.2013.1611

16 Chua TC and Merrett ND: Clinicopathologic factors associated with HER2-positive gastric cancer and its impact on survival outcomes-a systematic review. Int J Cancer 130(12): 2845-2856, 2012. PMID: 21780108. DOI: $10.1002 / \mathrm{ijc} .26292$

17 de Mello RA, Marques AM and Araújo A: HER2 therapies and gastric cancer: A step forward. World J Gastroenterol 19(37): 6165-6169, 2013. PMID: 24115812. DOI: 10.3748/wjg. v19.i37.6165

18 Kurokawa Y, Matsuura N, Kimura Y, Adachi S, Fujita J, Imamura H, Kobayashi K, Yokoyama Y, Shaker MN, Takiguchi S, Mori M and Doki Y: Multicenter large-scale study of prognostic impact of HER2 expression in patients with resectable gastric cancer. Gastric Cancer 18(4): 691-697, 2015. PMID: 25224659. DOI: 10.1007/s10120-014-0430-7

19 Hwang GY, Baek DW, Cho HJ, Lee SJ, Chae YS, Kang BW, Lee IH, Kim JG, Seo AN, Bae HI, Park KB, Park JY, Kwon OK, Lee SS and Chung HY: Elevated neutrophil-to-lymphocyte ratio predicts survival in patients with advanced gastric cancer treated with trastuzumab combination chemotherapy. Anticancer Res 38(5): 3151-3156, 2018. PMID: 29715156. DOI: 10.21873/ anticanres. 12578

20 Wilke H, Muro K, Van Cutsem E, Oh SC, Bodoky G, Shimada Y, Hironaka S, Sugimoto N, Lipatov O, Kim TY, Cunningham D, Rougier P, Komatsu Y, Ajani J, Emig M, Carlesi R, Ferry D, Chandrawansa K, Schwartz JD, Ohtsu A; RAINBOW Study Group: Ramucirumab plus paclitaxel versus placebo plus paclitaxel in patients with previously treated advanced gastric or gastro-oesophageal junction adenocarcinoma (RAINBOW): A double-blind, randomised phase 3 trial. Lancet Oncol 15(11): 1224-1235, 2014. PMID: 25240821. DOI: 10.1016/S14702045(14)70420-6

21 Kang YK, Boku N, Satoh T, Ryu MH, Chao Y, Kato K, Chung HC, Chen JS, Muro K, Kang WK, Yeh KH, Yoshikawa T, Oh SC, Bai LY, Tamura T, Lee KW, Hamamoto Y, Kim JG, Chin K, Oh DY, Minashi K, Cho JY, Tsuda M and Chen LT: Nivolumab in patients with advanced gastric or gastro-oesophageal junction cancer refractory to, or intolerant of, at least two previous chemotherapy regimens (ONO-4538-12, ATTRACTION-2): A randomised, double-blind, placebo-controlled, phase 3 trial. Lancet 390(10111): 2461-2471, 2017. PMID: 28993052. DOI: 10.1016/S0140-6736(17)31827-5

22 Shitara K, Doi T, Dvorkin M, Mansoor W, Arkenau HT, Prokharau A, Alsina M, Ghidini M, Faustino C, Gorbunova V, Zhavrid E, Nishikawa K, Hosokawa A, Yalçın Ş, Fujitani K, Beretta GD, Cutsem EV, Winkler RE, Makris L, Ilson DH and Tabernero J: Trifluridine/tipiracil versus placebo in patients with heavily pretreated metastatic gastric cancer (TAGS): A randomised, double-blind, placebo-controlled, phase 3 trial.
Lancet Oncol 19(11): 1437-1448, 2018. PMID: 30355453. DOI: 10.1016/S1470-2045(18)30739-3

23 Satoh T, Kang YK, Chao Y, Ryu MH, Kato K, Cheol Chung H, Chen JS, Muro K, Ki Kang W, Yeh KH, Yoshikawa T, Oh SC, Bai LY, Tamura T, Lee KW, Hamamoto Y, Kim JG, Chin K, Oh DY, Minashi K, Cho JY, Tsuda M, Tanimoto M, Chen LT and Boku N: Exploratory subgroup analysis of patients with prior trastuzumab use in the ATTRACTION-2 trial: A randomized phase III clinical trial investigating the efficacy and safety of nivolumab in patients with advanced gastric/gastroesophageal junction cancer. Gastric Cancer 23(1): 143-153, 2020. PMID: 31087200. DOI: 10.1007/s10120-019-00970-8

24 Lee S, Oh SY, Kim SH, Lee JH, Kim MC, Kim KH and Kim HJ: Prognostic significance of neutrophil lymphocyte ratio and platelet lymphocyte ratio in advanced gastric cancer patients treated with FOLFOX chemotherapy. BMC Cancer 13: 350, 2013. PMID: 23876227. DOI: 10.1186/1471-2407-13-350.

25 Jin H, Zhang G, Liu X, Liu X, Chen C, Yu H, Huang X, Zhang $\mathrm{Q}$ and $\mathrm{Yu}$ J: Blood neutrophil-lymphocyte ratio predicts survival for stages III-IV gastric cancer treated with neoadjuvant chemotherapy. World J Surg Oncol 11: 112, 2013. PMID: 23705622. DOI: $10.1186 / 1477-7819-11-112$.

26 Mantovani A, Allavena P, Sica A and Balkwill F: Cancer-related inflammation. Nature 454: 436-444, 2008. PMID: 18650914. DOI: 10.1038 /nature07205

27 Sachlova M, Majek O and Tucek S: Prognostic value of scores based on malnutrition or systemic inflammatory response in patients with metastatic or recurrent gastric cancer. Nutr Cancer 66(8): 1362-1370, 2014. PMID: 25356861. DOI: 10.1080/ 01635581.2014 .956261

28 Liu X, Chen S, Liu J, Xu D, Li W, Zhan Y, Li Y, Chen Y, Zhou $\mathrm{Z}$ and Sun X: Impact of systemic inflammation on gastric cancer outcomes. PLoS One 12(3): e0174085, 2017. PMID: 28358923. DOI: 10.1371 /journal.pone.0174085

29 Arigami T, Uenosono Y, Ishigami S, Okubo K, Kijima T, Yanagita S, Okumura H, Uchikado Y, Kijima Y, Nakajo A, Kurahara H, Kita Y, Mori S, Maemura K and Natsugoe S: A novel scoring system based on fibrinogen and the neutrophil-lymphocyte ratio as a predictor of chemotherapy response and prognosis in patients with advanced gastric cancer. Oncology 90(4): 186-192, 2016. PMID: 26981856. DOI: 10.1159/000444494

30 Xu BB, Lu J, Zheng ZF, Xie JW, Wang JB, Lin JX, Chen QY, Cao LL, Lin M, Tu RH, Huang ZN, Lin JL, Zheng CH, Huang $\mathrm{CM}$ and $\mathrm{Li}$ P: The predictive value of the preoperative $\mathrm{C}$ reactive protein-albumin ratio for early recurrence and chemotherapy benefit in patients with gastric cancer after radical gastrectomy: using randomized phase III trial data. Gastric Cancer 22(5): 1016-1028, 2019. PMID: 30739259. DOI: 10.1007/s10120-019-00936-w

$31 \mathrm{Lu} \mathrm{J,} \mathrm{Xu} \mathrm{BB,} \mathrm{Zheng} \mathrm{ZF,} \mathrm{Xie} \mathrm{JW,} \mathrm{Wang} \mathrm{JB,} \mathrm{Lin} \mathrm{JX,} \mathrm{Chen} \mathrm{QY,}$ Cao LL, Lin M, Tu RH, Huang ZN, Zheng CH, Huang CM and Li P: CRP/prealbumin, a novel inflammatory index for predicting recurrence after radical resection in gastric cancer patients: post hoc analysis of a randomized phase III trial. Gastric Cancer 22(3): 536-545, 2019. PMID: 30377862. DOI: $10.1007 / \mathrm{s} 10120-018-0892-0$

Received May 12, 2020

Revised June 13, 2020

Accepted June 16, 2020 